\title{
A proposed modification of the arterial switch operation: When better may not be the enemy of good
}

\author{
Petros V. Anagnostopoulos, MD
}

\footnotetext{
From the Department of Pediatric Cardiothoracic Surgery, American Family Children's Hospital, University of Wisconsin Hospital and Clinics, Madison, Wis.

Disclosures: Author has nothing to disclose with regard to commercial support.

Received for publication Feb 26, 2016; accepted for publication Feb 27, 2016; available ahead of print March 23, 2016.

Address for reprints: Petros V. Anagnostopoulos, MD, American Family Children's Hospital, University of Wisconsin Hospital and Clinics, H4/358 Clinical Sciences Center, 600 Highland Ave, Madison, WI 53792 (E-mail: petros@surgery.wisc.edu).

J Thorac Cardiovasc Surg 2016;151:e93-4

$0022-5223 / \$ 36.00$

Copyright (c) 2016 by The American Association for Thoracic Surgery

http://dx.doi.org/10.1016/j.jtcvs.2016.02.061
}

Al-Radi ${ }^{1}$ describes a modification of the arterial switch operation: A ring of aortic tissue is excised to shorten the ascending aorta. This aortic autograft is used to reconstruct the neopulmonary root. A trap door is not used for the coronary translocation. This technique, according to the author, achieves many desirable effects: improved coronary position; more-posterior placement of the aorta with less stretch on the branch pulmonary arteries; and potentially better aortic and pulmonary valve functions.

Introduced in 1982 by Jatene, the arterial switch has become the operation of choice for transposition of the great arteries and constitutes a major milestone in the history of neonatal congenital heart surgery. ${ }^{2}$ Despite the initial high operative mortality, the outcomes of the arterial switch improved considerably in the past 2 decades. In the past 4 years, the aggregate mortality in 109 centers that submitted more than 1800 arterial switch operations to the Society of Thoracic Surgeons Congenital Heart Surgery database was $2.6 \%$. More than $90 \%$ of these patients now survive into adulthood. The operation was developed as a solution to the long-term ventricular dysfunction and tricuspid valve regurgitation that was seen in patients long after the atrial switch operations. Thus far, the late performance of the left ventricle has justified the transition from the atrial to the arterial switch.

As a new cohort of congenital heart surgery survivors reaches adulthood, however, new long-term problems have been recognized that need to be addressed by the cardiologists and surgeons who care for these patients: neo-aortic root dilation with neo-aortic valve insufficiency; late silent coronary obstruction; and supravalvular and branch pulmonary artery stenosis. ${ }^{3,4}$ The incidence of late aortic root dilation and significant aortic insufficiency is low overall, but the number of case and case series reports of aortic root and valve reoperations is growing. Techniques reported include aortic valve replacement, composite aortic valve replacement, and valve-sparing aortic root replacement, a truly formidable and challenging operation.

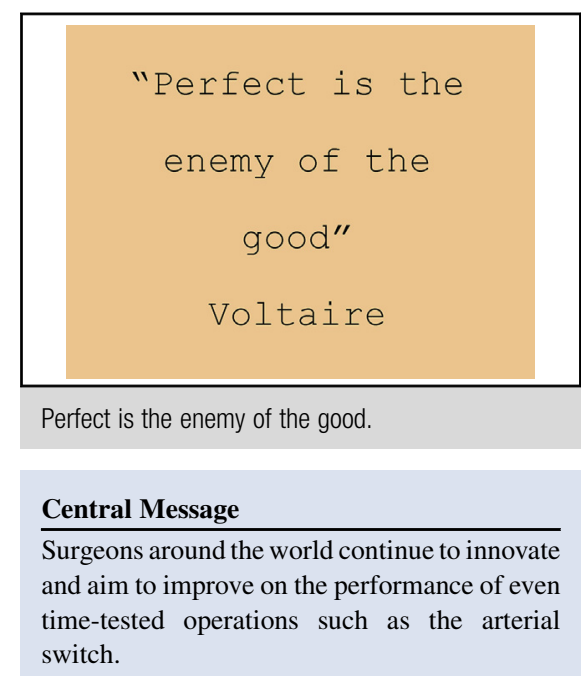

See Article page e89.

Although the use of the trap door coronary translocation technique has been implicated in the development of neoaortic root dilation, no conclusive evidence that this is true has been found. The neo-aortic root pathology is probably multifactorial and most likely is associated with the histopathologic characteristics of the pulmonary root and its response to the systemic circulation, rather than the operative technique used. In terms of the right side, a recent European study has pointed to main, rather than branch, pulmonary artery stenosis as the primary determinant of limitation in functional capacity of adult patients after the arterial switch operation.

The technical modification of the arterial switch proposed by Al-Radi ${ }^{1}$ is evidence that, every day, surgeons all over the world are continuously evaluating the performance of even the most successful congenital operations and are constantly trying to improve them. Here, better seems not to be the enemy of good. Moreover, because of technology and the global platform of our journals, scientific meetings, and Internet portals, the transfer of knowledge is much faster than ever before. For the current paper, one of the techniques utilized is the result of personal communication of the author with a surgeon who is practicing several thousand miles away from the author's primary institution.

This ability to identify late problems, communicate with each other, and develop modifications of our operations to improve the long-term outcomes is one of the most powerful forces of innovation in our field. However, with this 
power comes great responsibility. We need to critically evaluate the performance of our innovations. We need to continuously assess our results, to sort out which new ideas really work and which do not, and we should be prepared to report on our positive and negative long-term outcomes.

Al-Radi's ${ }^{1}$ modification is logical. However, more data are needed to assess the modification's true value. We await with great interest the follow-up paper from this group, to see if use of the aortic ring autograft results in better long-term growth of the neopulmonary root and less incidence of neo-aortic root dilation and neo-aortic insufficiency, along with improved outcomes, compared with the method used to perform one of the most successful corrective neonatal operations.

\section{References}

1. Al-Radi OO. Aortic ring autograft for reconstruction of the neo-pulmonary root in the arterial switch operation. J Thorac Cardiovasc Surg. 2016;151:e89-91.

2. Jatene AD, Fontes VF, Paulista PP, Souza LC, Neger F, Galantier M, et al. Anatomic correction of transposition of the great vessels. J Thorac Cardiovasc Surg. 1976;72:364-70.

3. Lo Rito M, Fittipaldi M, Haththotuwa R, Jones TJ, Khan N, Clift P, et al. Longterm fate of the aortic valve after an arterial switch operation. J Thorac Cardiovasc Surg. 2015;149:1089-94.

4. Baggen VJ, Driessen MM, Meijboom FJ, Sieswerda GT, Jansen NJ, van Wijk SW, et al. Main pulmonary artery area limits exercise capacity in patients long-term after arterial switch operation. J Thorac Cardiovasc Surg. 2015;150:918-25. 